\title{
Subsyllabic structure reflected in letter confusability effects in Korean word recognition
}

\author{
Chang H. Lee • Marcus Taft
}

Published online: 23 November 2010

(C) Psychonomic Society, Inc. 2010

\begin{abstract}
Korean subsyllabic structure was investigated by observing the pattern of responses arising from letter transpositions within a syllable in the Hangul script. Experiment 1 revealed no confusions when the onset and coda of one syllable of a disyllabic word were transposed. This was also the case in Experiment 2, where the transposition took place within a syllable having a coda composed of two consonants. However, confusion with the baseword was observed when the two consonants within the complex coda were themselves transposed. These results are taken to support the view that Hangul (and possibly all concatenating orthographic scripts) is processed based on its onset, vowel, and coda structure.
\end{abstract}

Keywords Letter position · Processing Hangul · Reading Korean $\cdot$ Transposed letter effect

Letter transposition confusability effects have become one of the widely debated topics in the current word recognition literature. Previous research has shown that transpositions of internal letters (e.g., warlus for walrus) are more disruptive than substitutions (e.g., walhus) in making a lexical decision, and are more facilitative in a masked priming paradigm (e.g., Perea \& Lupker, 2004). The importance of this topic is its theoretical implications as to how letters are coded during word processing.

\footnotetext{
C. H. Lee $(\bowtie)$

Department of Psychology, Sogang University,

Shinsu-Dong, Mapo-Gu,

Seoul 121-742, South Korea

e-mail: chleehoan@sogang.ac.kr

M. Taft

University of New South Wales,

Sydney, Australia
}

The existence of such a transposed letter (TL) effect is hard to reconcile with early accounts of letter position coding (e.g., Coltheart, Rastle, Perry, Langdon, \& Ziegler, 2001; Grainger \& Jacobs, 1996; McClelland \& Rumelhart, 1981; Seidenberg \& McClelland, 1989) whereby the representation for encoding a letter is different for different letter positions. Within such accounts, the $r$ of walrus is no more similar to the $r$ of warlus than to the $h$ of walhus. Models have therefore been developed to handle the TL effect.

The concept of spatial coding in the SOLAR model (e.g., C. Davis, 2010) can explain internal letter confusability effects by assuming a different level of activation depending on ordinal letter position. Specifically, the first letter of a word is activated with the highest level of activation, and the second is activated with the second highest level of activation, and so forth. Thus, there is little difference in activation between transposed internal letters and intact internal letters during word recognition. In the case of a word with substituted letters (e.g., walhus), the letter $h$ does not elicit any activation, making it more distinct from the baseword. The concept of open bigram in the SERIOL model (e.g., Whitney, 2001) can also explain TL effects. It argues that the access code of a word consists of ordinal bigrams both adjacent and nonadjacent (up to three letters apart). Thus, warlus would activate the bigrams $w a, w r, w l$, $a r, a l, a u, r l, r u, r s, l u, l s$, and $u s$, which, apart from $r l$, overlap with those of the baseword walrus. In contrast, walhus would activate only seven of the 12 bigrams making up walrus (i.e., those not involving the letter $r$ ). Another explanation for TL effects comes from the overlap model of Gómez, Ratcliff, and Perea (2008) where slot coding is imprecise such that $l$ presented in the fourth position will partly activate words that have $l$ in their third position. 
It is apparent from the website of M. Davis (2003) that whatever the explanation is for TL effects, it applies to many different languages, presumably all languages that use a linearly concatenating alphabetic orthography (such as all Indo-European languages). There are two other types of alphabetic orthography, however, that have failed to show TL effects. The first is the non-concatenating orthography of the Semitic languages Hebrew and Arabic, where the vast majority of words are composed of a threeconsonant root interleaved with other letters that provide syntactic information. Using a priming task in Hebrew and Arabic, respectively, Velan and Frost (2007) and Perea, abu Mallouh, and Carreiras (2010) found no facilitation of responses when the prime was a TL version of the target with two letters of the root transposed. It was therefore apparent that letter coding in these Semitic languages is organized in terms of the word root.

The second alphabetic orthographic system that has failed to reveal TL effects is the Korean Hangul script (Lee \& Taft, 2009). Hangul is a concatenating alphabetic script that is nonlinear. Words are separated into syllables, and each syllable has a predictable structure in terms of the positioning of its vowel and consonants within a square block. The vowel is always a variation of either a horizontal or a vertical line. The consonantal onset (which is always orthographically present, though sometimes silent) appears either above a horizontally oriented vowel or to the left of a vertically oriented vowel. The consonantal coda, when there is one, always appears at the bottom. For example, the Korean spelling of the word "Hangul" is 한글, where the first syllable 한 ("han") is composed of the onset $\overline{\bar{\sigma}}($ ("h") placed to the left of the vertically oriented vowel $\vdash$ ("a"), with the coda $\llcorner$ ("n") at the bottom. The second syllable 글 ("gul") is composed of the onset $\neg$ ("g") placed above the horizontally oriented vowel ("u") which, in turn, is placed above the coda $ᄅ$ ("l").

Lee and Taft (2009) observed little difficulty for Korean readers in making lexical decision responses to TLgenerated nonwords in Hangul (e.g., 납묵 generated from the word 남북, "nambuk", through the transposition of ㅁ and $ᄇ$ ), unlike the considerable difficulty experienced by English readers responding to nonwords of the same structure in English (e.g., warlus). The explanation given by Lee and Taft (2009) for the lack of TL effects in Korean was that letters are assigned to an orthographic onset, vowel, or coda position at an early stage of processing (see also Plaut, McClelland, Seidenberg, \& Patterson, 1996) and that, unlike linear scripts, such assignment is unambiguous in Hangul. The consonant at the top or top-left of the syllable block is always assigned to the onset slot and any consonant at the bottom of the block is always assigned to the coda slot.

In a linear script, such as English, only the onset of the first syllable and the coda of the last syllable are unambiguous in their assignment (e.g., the $w$ and $s$ of walrus), so assignment to the wrong slot can easily occur for the other letters. Even when one of the transposed letters is in an unambiguous position, some confusion can still occur because of the ambiguity of assignment of the other transposed letter. This was seen in the TL interference that Lee and Taft (2009) reported in English (but not Korean) when the two onsets or two codas were exchanged between syllables (e.g., ralwus or wasrul respectively).

One potential criticism of the conclusion drawn from the Hangul results, however, is that the transposition always took place across a syllable boundary. While this was also true in the English experiments that nevertheless showed TL interference, Hangul has a physical space between the syllables that might act as a barrier against transposition. Lee and Taft (2009) addressed this possibility by showing a significant, though reduced, TL effect for English despite it being physically structured in the same way as Hangul (i.e., "Hangulized" English). However, a concern remains that the unfamiliar structure of Hangulized English led to artificially induced processing confusions, such as jumping to the second syllable prior to the completion of the first.

For this reason, in order to establish the role of onsets and codas in the processing of Hangul, it is important to examine intra-syllabic transposition in Korean, which does not cross the syllable boundary. To this end, the first experiment transposed the onset and coda of either the first or second syllable of a two-syllable word.

\section{Experiment 1}

If the consonants within a Korean word have an identifiable role as onset and coda (Lee \& Taft, 2009), then the transposition of consonants within a syllable should not be confusable with the baseword when compared to a control condition which does not generate a real word through transposition. To test this, Experiment 1 exchanged the onset and coda of either the first syllable (e.g., 렵장 generated from the word 별장, "byuljang", through the transposition of ㅂ and ㄹ) or the second syllable (e.g., 신엽 generated from 신병, "sinbyung", through the transposition of $ᄇ$ and 0 ). If any evidence of TL confusion is to be observed, it is more likely to occur in the second syllable condition than in the first syllable condition. This is because of the possibility that a set of candidate words is activated by the first syllable through left-to-right processing and the second syllable is not processed in as detailed a bottom-up manner (e.g., Johnson \& Pugh, 1994). Thus, the baseword will be included in the set of candidates when its first syllable is intact and hence potentially be confused with the TL item if the physical position of the letters in the second syllable is of less importance. When the transposi- 
tion is in the first syllable, however, the baseword will not even enter the candidate set.

\section{Method}

Participants Twenty-six students enrolled in the Introductory Psychology class at the Korea University participated in the experiment to earn course credit. All had normal or corrected-to-normal vision.

Materials Transposed nonwords were created by swapping the onset and coda of the first or second syllable of a real word (e.g., 렵장 from 별장, or 신엽 from 신병). The real basewords were two syllables in length each of which had an onset, vowel, and coda. There were 20 items in both the first and second syllable transposition conditions with different basewords across condition. Mean baseword frequencies were 140.5 and 154.7 per million for the first syllable and second syllable conditions, respectively, which are within the medium frequency range according to the Korean Word Database (2001).

The control nonwords were constructed in line with Lee and Taft (2009) by substituting one letter of the TL item with another; in this case, the first consonant of the second syllable (e.g., 렵상 as a control for 렵장, and 신겹 as a control for 신엽). The reason for changing a consonant in the second syllable was to keep the first syllable intact because of its important role in word recognition (e.g., Taft \& Forster, 1976). Neighborhood size (e.g., Coltheart, Besner, Jonasson, \& Davelaar, 1979) and bigram frequency were controlled between the experimental condition and control conditions.

Within a Latin-Square design, each condition was split into two lists in order to avoid having the same subjects see a TL nonword and its similar-looking control. Therefore, each list had ten items in each of the four conditions. The two lists also included the same 40 distractor words which were of the same structure as the nonword items. The same 20 practice items were also included in each list.

Procedure Participants were instructed to decide whether each of the items appearing at the center of a 586 PC computer screen was a real Korean word or not. Both accuracy and speed were emphasized. Items were presented in a different randomized order to each participant using DMDX display software (Forster \& Forster, 2002). Exposure duration was $250 \mathrm{~ms}$, and there was a $1 \mathrm{sec}$ inter-trial interval.

Results and discussion

Any reaction times exceeding two and half standard deviations from the mean for each participant were removed, constituting $1.9 \%$ of trials. Table 1 presents the mean RTs and error rates for the two TL conditions and their controls.

A $2 \times 2 \times 2$ ANOVA was carried out, with the withingroup variables being TL vs. control and syllable position (first vs. second), with the between-groups factor being Lists. The latter is not reported because it was simply required for the Latin-Square design and not meaningfully interpretable. The only significant effect in either the RT or error measure was the main effect of syllable position for RT, $F_{1}(1,25)=17.9, p<0.001, F_{2}(1,19)=6.9, p<.05$, with disruption to the first syllable leading to faster nonword classification times than to the second. The main effect of syllable position showed a trend on the error measure, $F_{1}(1,25)=2.40, p>0.1, F_{2}(1,19)=2.02, p>$ 0.1 , but all other $F$ s were $<1$. The mean RT for word trials was $507 \mathrm{~ms}$ with an error rate of $8.0 \%$.

These results replicate the previous failure of Lee and Taft (2009) to find transposition effects in Hangul, but this time within a syllable rather than between syllables. Even though the intact first syllable of the disrupted second syllable condition slowed down response times relative to the disrupted first syllable condition, this was equally true when the second syllable was a transposed version of the second syllable of the baseword as when it was not. This main effect of syllable position presumably arose from the fact that the frequency of the first syllable was much lower in the first syllable conditions (17.7) than in the second (111.8), making the former easier to discriminate from real words. Although not of central interest, the fact that at least one effect was significant indicates that the experimental design had sufficient power to detect at least some behavioral effects.

Before concluding that the results support the idea of positional specificity in Korean, however, an alternative explanation needs to be considered. In particular, the TL disruption in the present experiment left only one of the three elements of the syllable intact. Even in a linear orthography such as English, there is likely to be little TL interference for three-letter monosyllabic words (e.g., sti is unlikely to be confused with sit). Indeed, in an experiment where two elements of a single Chinese character were transposed, Taft, Zhu, and Peng (1999) failed to find TL interference when that character contained three elements, but did find interference when it contained four. Thus, there may only be confusion with the baseword when at least half of its components are intact. Although the use of twosyllable words in the present experiment meant that twothirds of the baseword was intact, it is possible that the largest unit of orthographic representation in Korean is the syllable (with whole-word identification occurring through the combined activation of those representations) and, hence, only a third of the relevant unit was intact. In fact, 
Table 1 Mean lexical decision times and \% error rates (ER) based on the participant analysis of the Korean nonwords in experiment 1 (confidence intervals in parentheses)

\begin{tabular}{llll}
\hline & TL & Control & Size of effect \\
\hline 1st Syllable & 렵장 & 렵상 & \\
& $521 \mathrm{~ms}$ & $515 \mathrm{~ms}$ & $6 \mathrm{~ms}( \pm 33.8)$ \\
2nd Syllable & $7.3 \%$ & $8.1 \%$ & $0.8 \%( \pm 2.8)$ \\
& 신엽 & 신겹 & \\
& $554 \mathrm{~ms}$ & $553 \mathrm{~ms}$ & $1 \mathrm{~ms}( \pm 29.6)$ \\
& $10.0 \%$ & $10.8 \%$ & $-0.8 \%( \pm 3.0)$ \\
\hline
\end{tabular}

the same argument could be used to explain the lack of TL effects in Hebrew and Arabic (Perea et al., 2010; Velan \& Frost, 2007) because the basic processing unit is the root which contains only three elements. The second experiment reported here includes an examination of whether the lack of TL effects in Korean can be explained in terms of the small number of elements within a syllable.

\section{Experiment 2}

It is possible for a word written in Hangul to have two consonants in the coda position (e.g., 닭, meaning "chicken"), which therefore creates a syllable composed of four elements. Such syllables provide the opportunity to further test the idea that it is the specificity of onset or coda position in Hangul that prevents TL effects from occurring. In particular, exchanging the onset of the syllable with the first consonant in the coda (e.g., 랃 generated from 닭 through transposition of $ᄅ$ and $ᄃ$ ) should still fail to produce TL effects despite the fact that half of the baseword remains intact. Importantly, however, exchanging the two consonants in the coda is the one situation in Hangul where TL interference might be observed (e.g., 닥ㄹ generated from 닭 through transposition of $ᄅ$ and $\neg)$. The reason for predicting this is because the exchanged consonants fill the same subsyllabic slot (i.e., the coda slot) and this leads to ambiguity in assigning them to their correct position. Experiment 2 tests these two types of transposition.

\section{Method}

Participants The participants were 26 students enrolled in the Introductory Psychology class at Ajou University. All had normal or corrected-to-normal vision. They received course credit for participating.

Materials Basewords were seven monosyllabic words(e.g., 닭) and 13 disyllabic words (e.g., 젊음) that included a syllable having a pair of consonants in the coda position. The TL nonwords were generated either by swapping the left-hand consonant of the coda and the consonant in the onset position (e.g., 랃 from 닭) or by swapping the two consonants of the complex coda (e.g., 달 from 닭). The frequency of the basewords was 30.4 per million, which is within the low to middle frequency range (Korean Word Database, 2001). Control nonwords for each condition were created by substituting the second of the exchanged consonants with another consonant that did not create a real word through transposition (e.g., 락 as the control for 랃, and 담 as the control for 달). In all but two of the nonword items, the complex coda was non-existent in Hangul. In constructing the stimuli, the coda consonants were made as large as possible within the range of acceptability in order that they would not be very different in size to the onset.

Thus, there were 20 onset-coda transposition and 20 coda-coda transposition items and an equal number of control items for each condition. These 80 nonwords were divided into two lists within a Latin-Square design, so that no participant received both a TL item and its control (which had three of their four elements in common). The same participant did receive both the onset-coda and codacoda transpositions of the same baseword, but these were less similar in appearance to each other than a TL item and its control (with only one of the four elements being the same).

Each list also included 20 nonword fillers, which did not have two consonants in the coda position, as well as 60 distractor words. Half of the distractor words included a coda with two consonants (e.g., 삿, meaning "price") and, for comparability with the nonwords, these coda consonants were also made as large as possible within the range of acceptability. None of the basewords of the nonword conditions was included amongst the distractor words. There were 16 practice items.

Procedure The procedure was the same as in experiment 1.

Results and discussion

Across all participants, $0.8 \%$ of trials exceeded two and half standard deviations from the mean and were removed. Mean RTs and error rates are presented in Table 2.

A $2 \times 2 \times 2$ ANOVA was carried out, with the withingroup variables being TL vs. control and type of transposition. The between-groups factor of lists is again not reported. No significant effects were found for the RT measure, $F(1,25)=$ 
Table 2 Mean lexical decision times and \% error rates (ER) based on the participant analysis of the Korean nonwords in experiment 2 (confidence intervals in parentheses)

TL

Control

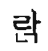

$515 \mathrm{~ms}$

$513 \mathrm{~ms}$

$2 \mathrm{~ms} \quad( \pm 11.6)$

$13.3 \%$

$16.1 \%$

$-2.8 \% \quad( \pm 3.2)$

Coda-coda

달

\section{담}

$26.1 \%$

$484 \mathrm{~ms}$

$1 \mathrm{~ms} \quad( \pm 14.5)$

$15.3 \%$

$10.8 \%$

$( \pm 5.3)$
1.93 for transposition type, and $\mathrm{F}<1$ for TL vs. control. In the analysis of errors, the main effect of transposition type was significant, $F_{1}(1,25)=14.2, p<0.001, F_{2}(1,19)=6.1$, $p<0.05$, but not the main effect of TL vs. control, $F \mathrm{~s}<1$. More importantly, the two factors significantly interacted, $F_{1}(1,25)=10.6, p<0.01, F_{2}(1,19)=8.4, p<0.01$, with TL interference for the coda-coda swap being significant, $F_{1}(1,25)=17.6, p<0.001, F_{2}(1,19)=9.6, p<0.05$, while the reverse trend for the onset-coda swap was not, $F_{1}(1,25)=$ $1.96, \mathrm{p}>0.1, F_{2}<1$. The mean RT for word trials was $503 \mathrm{~ms}$ with an error rate of $12.9 \%$.

It appears from the error data that, as predicted, it is possible to find a TL effect in Korean, but only when the transposed letters serve the same subsyllabic function within the same syllable. Under such conditions, there is some ambiguity about the assignment of the letter to its correct position, namely, whether the consonant should be assigned to the first or second coda position. This is despite the fact that the complex coda produced by the transposition does not exist in Hangul (e.g., ᄀᄅ). While any consonant at the bottom of a syllabic block unambiguously takes the role of a coda, the correct letters of a complex coda presented in the wrong order still have the potential to activate that complex coda, implying imprecision in the coding of position within the coda.

The fact that TL interference was again absent when a consonant in the onset position was exchanged with a consonant in the coda position eliminates several alternative explanations. First, it demonstrates that the failure to find an effect in Experiment 1 was not merely the result of there being insufficient letters of the syllable remaining intact, because only half of the letters were disrupted in Experiment 2. Similarly, the TL effect seen in the coda-coda swap condition of Experiment 2 cannot be ascribed simply to there being more of the syllable intact than in previous experiments, because the same amount of the syllable was intact in the onset-coda swap condition.

In addition, the strength of the TL effect for the codacoda nonwords might have arisen from the fact that the transposed letters were physically adjacent to each other. However, the transposed letters were also physically adjacent in the onset-coda swap condition, albeit vertically. Although it might be argued that the TL effect is only found for transpositions that occur in a horizontal plane, unpublished research in our laboratory provides no evidence for TL effects in Hangul when an onset is transposed with a vowel, even though those two letters are horizontally adjacent. For example, 강송 is a nonword created from the word 방송 by transposing the onset $(\bullet)$ and vertically oriented vowel $(t)$ of the first syllable. In an experiment of equivalent design to that of Experiment 1 here, neither RTs nor error rates showed any evidence of confusion between the TL nonword and its baseword regardless of the syllable in which the transposition occurred, all $F_{\mathrm{s}}<1$. Therefore, it seems that not all horizontal transpositions generate a TL effect in Hangul. Moreover, in order to argue that TL effects only occur for horizontal transpositions, it would need to be shown that the TL effect in a linear script disappears when the letter-strings are presented vertically, which is something that is yet to be established.

\section{General discussion and conclusions}

Hangul is probably the only orthographic system whereby the onset, vowel, and coda positions can be unambiguously determined from the orthographic input. The two experiments reported here provide further support for the claim of Lee and Taft (2009) that such specification of subsyllabic orthographic structure prevents confusion when letters are placed in an incorrect position. Evidence for such TL confusion is only found when the misplaced letters fill the same subsyllabic role, especially within the same syllable. Swapping an onset with a coda does not lead to activation of the baseword, even when half of the syllable remains intact (Experiment 2) and even when the transposed letters are adjacent to each other within a disyllabic word (Lee \& Taft, 2009).

The implication of these results is that subsyllabic structures play an important role in word recognition. While the research is primarily focused on the nature of word recognition in Hangul, there are potential implications for the reading of other alphabetic scripts. In linearly concatenated alphabetic systems, the location of subsyllabic structures is not physically marked and TL confusion is rife. While this is especially true for internal letters, even the status of the initial or final letter is more ambiguous than in Hangul. The first letter of a Hangul word is guaranteed to be an onset because 
even a silent onset is marked by a grapheme (i.e., ㅇ). In other languages, the first letter might be a vowel rather than an onset, hence creating some ambiguity in its status. While it is true that the final letter of a Hangul word might be a vowel rather than a coda, it is obvious when this is the case because the vowel is so physically distinct (being a variant of either a horizontal or a vertical line) and also because the syllable will then be composed of only two graphemes.

It might therefore be concluded that TL confusions are a symptom of ambiguity in the assignment of letters to their appropriate onset, vowel, or coda slot at the early stages of word recognition, and this points to the critical involvement of such subsyllabic structures in the lexical processing of all concatenating orthographies. Hangul only reveals TL confusion when assignment of the letter to its subsyllabic slot is ambiguous, namely, for a complex coda where there are two possible positions within the one slot. Most current accounts of letter position assignment ignore the role that the letters take as subsyllabic units within the word. The present research suggests that this is an oversight.

Authors Note This research was supported by the Original Technology Research Program for Brain Science through the National Research Foundation of Korea(NRF) funded by the Ministry of Education, Science and Technology(2010-0029268 ), and partly by Sogang University Research Grant(201010034.01) to the first author, and a Discovery grant awarded by the Australian Research Council to the second author.

\section{References}

Coltheart, M., Besner, D., Jonasson, J. T., \& Davelaar, E. (1979). Phonological encoding in the lexical decision task. The Quarterly Journal of Experimental Psychology, 31, 489-507.

Coltheart, M., Rastle, K., Perry, C., Langdon, R., \& Ziegler, J. (2001). DRC: A Dual Route Cascaded model of visual word recognition and reading aloud. Psychological Review, 108, 204-256.

Davis, C. J. (2010). The spatial coding model of visual word identification. Psychological Review, 117, 713-758.
Davis, M. (2003). Personal web page via the Cognition \& Brain Sciences Institute, University of Cambridge. Retrieved from: www.mrc-cbu.cam.ac.uk/people/matt.davis/Cmabrigde/

Forster, K. I., \& Forster, J. C. (2002). DMDX display software. Retrieved from: www.u.arizona.edu/ kforster/dmdx/dmdx.htm

Gómez, P., Ratcliff, R., \& Perea, M. (2008). The overlap model: A model of letter position coding. Psychological Review, 115, 577-601.

Grainger, J., \& Jacobs, A. M. (1996). Orthographic processing in visual word recognition: A multiple read-out model. Psychological Review, 103, 518-565.

Johnson, N. F., \& Pugh, K. R. (1994). A cohort model of visual word recognition. Cognitive Psychology, 26, 240-346.

Korean Word Database (2001). 21th century Sejong Project Corpus. The National Institute of the Korean Language, Seoul: Korea

Lee, C. H., \& Taft, M. (2009). Are onsets and codas important in processing letter position? A comparison of TL effects in English and Korean. Journal of Memory and Language, 60, $530-542$.

McClelland, J. L., \& Rumelhart, D. E. (1981). An interactive activation model of context effects in letter perception: Part 1 . An account of basic findings. Psychological Review, 88, 375407.

Perea, M., abu Mallouh, R., \& Carreiras, M. (2010). The search for an input coding scheme: Transposed letter priming in Arabic. Psychonomic Bulletin \& Review, 17, 375-380.

Perea, M., \& Lupker, S. J. (2004). Can CANISO activate CASINO? Transposed-letter similarity effects with non-adjacent letter positions. Journal of Memory and Language, 51, 231-246.

Plaut, D. C., McClelland, J. L., Seidenberg, M. S., \& Patterson, K. (1996). Understanding normal and impaired word reading: Computational principles in quasi-regular domains. Psychological Review, 103, 56-115.

Seidenberg, M. S., \& McClelland, J. L. (1989). A distributed, developmental model of word recognition and naming. Psychological Review, 96, 523-568.

Taft, M., \& Forster, K. I. (1976). Lexical storage and retrieval of polymorphemic and polysyllabic words. Journal of Verbal Learning and Verbal Behavior, 15, 607-620.

Taft, M., Zhu, X., \& Peng, D. (1999). Positional specificity of radicals in Chinese character recognition. Journal of Memory and Language, 40, 498-519.

Velan, H., \& Frost, R. (2007). Cambridge University versus Hebrew University: Impact of letter transposition on reading English and Hebrew. Psychonomic Bulletin \& Review, 14, 913-918.

Whitney, C. (2001). How the brain encodes the order of letters in a printed word: The SERIOL model and selective literature review. Psychonomic Bulletin \& Review, 8, 221-243. 